\title{
Cotidiano
}

\section{QUANDO O EXCESSO DE AMOR PREJUDICA O DESENVOLVIMENTO HUMANO}

Edneia de Oliveira Alves (1) Maysa Suelma Palmeira Leite Rocha (2)

\begin{abstract}
Resumo
$\mathrm{O}$ artigo a seguir relata recortes da história de vida de uma surda que teve uma educação super-protetora. As experiências vividas por ela e apresentadas aqui são analisadas sob o enfoque de teorias que abordam o papel da família no desenvolvimento social, intelectual e emocional de uma pessoa. Acredita-se que a educação super-protetora, embora seja com a intenção de evitar de sofrimento, prejudica a autonomia e o desenvolvimento humano dos indivíduos. No caso da surdez, existe a capacidade de adaptação das normas sociais e da autonomia, negá-lo esse tipo de preparo é uma forma de torná-lo incapaz de fato.
\end{abstract}

\section{Palavras-chave: Amor, Educação, Necessidade especial}

Este artigo pretende, através de um relato de vida pessoal expor as conseqüências que a super-proteção pode trazer ao desenvolvimento social, individual e emocional de um deficiente, mais especificamente de um surdo.

Antes faz-se necessário compreender que a super-proteção é um comportamento que pode prejudicar o desenvolvimento humano, pois muitos pais perdem a medida da proteção e esquecem de preparar os filhos para enfrentar as adversidades da vida. Esse tipo de comportamento é comum ser encontrado em casos em que a família precisa lidar com filhos com deficiência. Nessas famílias, muitos pais são incapazes de perceber que o seu desejo de aliviar o sofrimento de seu filho em todas as circunstâncias acabam expondo-os a maior 
sofrimento. Perske (1972), um dos pioneiros do movimento de integração e normalização de pessoas com deficiências, alerta que:

A super-proteção ameaça a dignidade humana, e faz com que essas pessoas sejam impedidas de experimentar as situações de risco da vida cotidiana que são necessárias para o crescimento e desenvolvimento humano normal...Negar a qualquer pessoa sua cota justa de experiências que envolvam risco é modelá-las ainda mais para uma vida saudável (p.195 e 196).

Este artigo também centra sua discussão nas conseqüências que uma educação doméstica pode trazer para a formação social, individual e emocional de uma criança. Mieiro $(2003,37)$ afirma que:

Estudos feitos em diversas áreas nos levou a constatar que a família é o "berço do caráter" é a melhor das escolas para o bom desenvolvimento infantil e é esta relação entre criança e o meio familiar, principalmente a mãe, que vão influir nos aspectos neuropsicológicos.

É no ambiente familiar que os comportamentos são aprendidos de forma que as crianças possam se tornar adultos sociáveis. Assim a socialização primária, é tarefa primordial da família moderna Ocidental, pois assegura o ingresso e participação da criança no mundo social, e consiste no processo de aprendizagem e internalização do mundo objetivo, possibilitando a compreensão de si, dos outros e do mundo social como dotado de sentidos.

Desta maneira a socialização da criança ao seu mundo social é filtrado pelos seus mediadores. Em outras palavras, o mundo é "apresentado", "traduzido" para a criança por intermédio dos pais que ensinam as regras do jogo social. Nesse processo a criança "assume" o mundo dos seus pais. Entretanto, não internaliza esse mundo passivamente, mas de uma maneira crítica e dinâmica: aceita, reelabora e rejeita.

Esse processo de aprendizagem se inicia nos primeiros anos de vida, com o conhecimento e domínio do próprio corpo. A família começa ensinando a comer, a andar, a controlar os esfíncteres e a falar. Ou seja, a criança vai adquirindo um conhecimento progressivo de si e do mundo. De acordo com Gomes (1994), 
A família transmite às nova gerações, especialmente à criança, desde o nascimento, padrões de comportamento, hábitos, usos, costumes, valores, atitudes, um padrão de linguagem. Enfim, maneiras de pensar, de se expressar, de sentir, de agir e reagir que lhe próprios, naturais. Não bastasse tudo isso ela promove a construção das bases da subjetividade, da personalidade e da identidade. Deriva disso a enorme importância da família tendo em vista a vida futura de cada criança; ela, a família, constrói os alicerces do adulto futuro. (p. 58-59)

É importante ressaltar que o processo de socialização primária também se caracteriza pela forte carga emocional, predominando aspectos emocionais e afetivos, pois os laços afetivos existentes entre pais e filhos são fortes, e as vivências são intensas e marcadas pela emotividade que será levada para o resto de nossas vidas, as marcas dessa socialização.

John Bowlby (2002), introduziu o termo interação em 1958, ampliando a idéia de intercâmbio do bebê com a mãe. Ele considerava não apenas o aspecto da gratificação oral e redução da tensão enquanto satisfação de necessidades fisiológicas do bebê através da mãe, como se pensava até então, mas também passou a supor a presença do apego na criança como uma modalidade básica e inata do comportamento da espécie humana. Além disso, gradualmente, a criança constrói uma imagem coerente de si e do mundo através da reciprocidade que estabelece na relação com a figura de apego. Assim sendo, comportamento da figura de apego serve como modelo para que a criança desenvolva um determinado comportamento interativo ao receber feedbacks de seus próprios comportamentos.

Em se tratando do artigo em questão, o relato logo após abordado terá como fim mostrar para as famílias que a super-proteção não contribui para o crescimento positivo de uma pessoa. A educação doméstica deve ser sempre repensada e avaliada sob a perspectiva de contribuição positiva para o desenvolvimento das crianças das famílias.

$\mathrm{O}$ artigo relata recortes da história de vida de uma surda que experienciou uma educação doméstica super-protetora, que tem em torno de 40 anos de idade, surda moderada dos dois ouvidos, separada, mãe de um filho e tem o nível fundamental II incompleto.

Sua vida não corre nos padrões das normas sociais: não cumpre horários certos de dormir, acordar, sair e chegar em casa, não tem rotina em atividades que exijam responsabilidade a cumprir e com certa rotina, como por exemplo: atividades domésticas, não tem objetivos traçados e seu comportamento muitas vezes são inadequados para sua idade. Maiores informações sobre dados pessoais não são informados para a preservação do sigilo de identidade do sujeito e das pessoas relacionadas a ela. 
Muitos comportamentos de uma criança ainda são observados nessa surda depois de adulta. Esses comportamentos que deveriam ter sido moldados foram mantidos, um dos comportamentos caracteristicamente de criança e que se pôde observar na fase adulta foi com relação ao mecanismo utilizado por ela para conseguir satisfazer os seus anseios.

$\mathrm{Na}$ infância ela sempre que queria alguma coisa utilizava como estratégia primeira o pedido à mãe, quando ele não era atendido um espetáculo era montado: ela gritava muito em qualquer lugar e com qualquer pessoa e esperneava no chão até que a mãe se cansava e atendia seu pedido. Esse comportamento da mãe algumas vezes era repetidos por alguns familiares. Todos não sabiam como reagir e cediam às suas chantagens. $\mathrm{O}$ comportamento das pessoas de fora era sempre regrado por pena e sempre faziam os suas vontades.

$\mathrm{Na}$ fase adulta, esse comportamento se repetia tanto com a mãe quanto com o marido. Porém, as pessoas não sentem mais pena e preferem manter distância dela. Percebe-se, então, que ela sente muita solidão, mas, infelizmente não sabe respeitar as pessoas de modo que as mantenham próximas.

Conforme Tannure $(2007,4)$, pode-se explicar essa evitação de sofrimento por parte da mãe porque,

Quando o psiquismo está dominado pela sensação de ser habitado por objetos persecutórios e pela angústia de aniquilamento, a relação da mulher com sua criança e com as pessoas, de modo geral, será dominada pela desconfiança. Haverá desconfiança acerca da permanência do amor dos objetos, uma perturbação da própria capacidade de amar (havendo a presença constante de sentimentos de raiva em relação ao filho) e um afastamento social em razão do temor de ser hostilizada, uma vez que os objetos estão sob suspeita, por serem sentidos como persecutórios.

Segundo Amaral (1995), a super-proteção ao filho com deficiência pode gerar ambivalência de sentimentos dos pais em relação a esses "filhos -problema", que oscilam entre o amor e a raiva, a alegria e o sofrimento, a aceitação e a rejeição. Para Glat (2003) esses sentimentos fazem partem da vivência de todo pai com filhos que tenham necessidades especiais, porque ao mesmo tempo que ele tem pena de seu filho, ele sente raiva desse filho que não era esperado, que complicou sua vida e lhe dá a uma serie de atribuições diárias. Mas para compensar esse sentimento de raiva pelo filho, esse pai tenta mostrar que realmente se preocupa com esse filho, e então passa a surper-protegê-lo permanentemente. Esta atitude como já foi discutido, torna o filho ainda mais dependente, limita o seu desenvolvimento 
pessoal, que por sua vez provoca mais sentimentos de frustração e raiva, formando um circulo vicioso e continuo.

No caso em questão, o sentimento de raiva parece ser inconsciente e projetado para o marido, do qual se separou, e para a outra filha (sem necessidades especiais). A mãe, ao tentar proteger a filha surda, acabava punindo a outra filha. À medida que cedia direitos, de espaço e outros, excessivos à filha surda retirava da filha ouvinte

Um dos comportamentos da mãe que pode ser interpretado como reação à condição de ter uma filha surda, e que era freqüente, era a tentativa de esconder a surdez em locais públicos. Sempre que se saía na rua era proibido gesticular. Sempre que era preciso haver comunicação com a surda os gestos eram bem curtos e rápidos para que as pessoas não percebessem que se tratava de uma surda.

Assim, numa tentativa de defender a filha surda da rejeição social, a mãe acabou reforçando a supervalorização a sua condição especial de indivíduo com necessidades especiais, e restringiu ainda mais sua inclusão no meio social mais amplo.

Com relação às conseqüências da educação doméstica na infância, provavelmente em decorrência das respostas que recebia na sua infância, a surda sempre fazia exigências da família de forma que se pressupunha que o entendimento dela era que o mundo tinha que se curvar às suas vontades e as pessoas deveriam se moldar às suas necessidades.

Essas idéias vão de encontro com a percepção que muitos surdos e seus familiares têm: eles acreditam que as pessoas que estão em volta do surdo devem estar de prontidão para atender às suas necessidades e caprichos, como uma forma de caridade, quando na verdade pode ocorrer, não premeditadamente, uma escravização. Não há quem consiga estar a dispor de outro a qualquer momento para o que ele julgar ser preciso. As pessoas não devem ser servos dos surdos, mas, ajudá-lo quando puder e quando precisar. Isso quer dizer, que as pessoas que se dispõem a ajudar um surdo tem limites para tal e que nem toda hora o surdo precisa de ajuda. Caso as medidas exigidas por lei entrem em vigor de maneira eficaz a dependência do surdo com relação às pessoas que estão a sua volta diminui e a sua relação com essas pessoas pode melhorar e propiciar prazer e desenvolvimento humano.

Esse relato mostra um comportamento posterior ao diagnosticado por Tannure (2007, 5) que afirma: 
Quando a mulher tem um filho deficiente, muitas vezes ela negará a deficiência deste, por ser para ela uma realidade penosa. Quando isso ocorre haverá, para a mãe uma expectativa de que esse filho possa desempenhar tarefas que estão muito além de sua capacidade real, ou então haverá a ilusão de que a deficiência seja algo passageiro e passível de cura. Sendo assim, esse filho muitas vezes será submetido a vários exames ou a consultas com diversos profissionais, na esperança de que se obtenha um outro diagnóstico.

Todo esse processo de tentativa de mudar a realidade da surdez da filha aconteceu na primeira e segunda infância. Quando a mãe se viu impossibilitada de novas tentativas por fatores econômicos, passou a ter o comportamento que vem sendo relatado nesse artigo.

O caso relatado aqui demonstra que houve uma sobreposição da super-proteção sobre a expectativa de desempenho de tarefas, o que foi prejudicial para o desenvolvimento social, individual e emocional da surda. Por outro lado tal mãe nutriu sempre a esperança de que a filha passasse a escutar, tanto que ela - depois de se negar - sente muita dificuldade de aprender a Libras.

Essa realidade é parcialmente referendada nos argumentos de Tannure $(2007,5)$ quando afirma:

Outro recurso defensivo utilizado será a formação reativa, que transforma o afeto representativo de um perigo pulsional em seu oposto. Assim, a ira é substituída por um amor extremado, super-protetor, que faz com que a mãe assuma quase sempre todos os cuidados referentes ao filho e passe a nutrir uma crença de que somente ela é adequada para cuidar dele.

A mãe nunca aprendera a comunicar-se com a filha surda, a não ser para ordens práticas do dia-a-dia, aquelas das quais não conseguia fugir, as outras era repassada pela irmã.

$\mathrm{O}$ que o surdo precisa é que haja profissionais capacitados para atender às suas reais necessidades. Quando se fala de comunicação, que haja um profissional intérprete, ou se falar de escola, que tenha professores capacitados para ensiná-los, e ainda, em se tratando de atendimento médico, que se tenha pessoas capacitadas a atender pacientes com as especificidades necessárias. Também é importante existir profissionais habilitados para apoiar a família da pessoa com deficiência no aspecto emocional. Deve existir um espaço para que os pais e outros familiares possam trazer suas dúvidas, frustrações e ansiedades, a fim de que esses sentimentos sejam trabalhados e não os imobilizem. Ao mesmo tempo é necessário 
fornecer a essas famílias informações precisas e atualizadas sobre a condição de seu filho, com o objetivo de orientá-los nas situações problema do dia a dia.

No caso da surda em questão, não era cobrado dela nenhum tipo de responsabilidade. Ela não podia freqüentar aulas por falta de condição financeira para mantê-la em uma escola adequada para surdos, mas, também não lhe era atribuído nenhum outro tipo de responsabilidade, nem com as próprias roupas, por exemplo. Nunca foi cobrado que cumprisse horário, a não ser o de deitar-se, mas, não de acordar. Ela nunca entendeu, com exceção de que seja de interesse apenas dela, que as pessoas quando marcam um compromisso devem chegar na hora marcada. Os horários que se tratam de convenção social ela não os cumpre ainda. A justificativa para a não cobrança de responsabilidade era de que ela não seria capaz de assumir, pois, era doente.

Por trás do comportamento super-protetor da mãe existia a necessidade de compensação pela deficiência auditiva. A escolha foi evitar qualquer tipo de contrariedade para que as duas fossem poupadas de aborrecimentos. Era como se existisse um cristal frágil que deveria ter todo o aparato para não quebrar. Porém, os resultados dessa escolha da forma de educar a filha não foi dos melhores.

Toda a inteligência para aprender conteúdos de disciplinas específicas se perdeu por trás dessa super-proteção e da falta de escolarização na infância. Se não fosse a superproteção, talvez o senso de responsabilidade ajudasse-a a terminar pelo menos o nível fundamental, no qual ela se matrícula e abandona no meio do ano. O que se espera de uma pessoa adulta é que: uma vez que a pessoa se determina a fazer algo e tem disciplina para tal, seus objetivos são alcançados. Não é o caso dessa surda, que traça objetivos e desiste no percurso. Outra possibilidade é que talvez ela não tenha a escolarização como um valor importante para a sua vida, até porque ela sempre foi impedida de freqüentar a escola porque a que tinha acesso era regular para ouvintes.

Muito sobre a vida foi deixado de ser ensinado para ela, como forma de poupá-la dos problemas para suprir a falta da audição e do aprendizado da Língua Portuguesa oral. O surdo precisa enfrentar as diversas dificuldades que são impostas pelo sistema. Quando o surdo é preparado para enfrentar tais problemas e tem apoio para isso, ele consegue transpor as barreiras.

A sociedade precisa de fato, se moldar às necessidades dos deficientes, mas, em questões muito específicas, como é previsto na lei da acessibilidade $\mathrm{n}^{\mathrm{o}} 10.098 / 2000$ e da Libras $n^{\circ}$ 10.436/2002 por exemplo. A lei da acessibilidade prevê modificações arquitetônicas para acessibilidade da peça como mobilidade reduzida nos diversos ambientes da sociedade. 
A lei Libras, regulamentada pelo decreto 5.626/2005 reconhece a língua de sinais como língua materna do surdo, o direito a comunicabilidade nos diversos espaços sociais, para tanto exige a presença de intérprete de Libras em espaços de comunicação entre surdos e ouvintes, inclui a disciplina de Libras em caráter de obrigatória nos cursos de licenciatura, exige a formação de professores, instrutores e tradutor intérprete de Libras entre outras medidas.

A adaptação não deve ocorrer em função dos desejos pessoais construídos pelos pais e familiares do deficiente, ou pelo próprio deficiente, pois existe uma estrutura e valores sociais gerais que devem ser respeitados. O surdo também é capaz de assumir responsabilidades e de adaptar-se a algumas normas sociais. Mas, para isso precisa receber afetividade e uma educação, doméstica e escolar, que o prepare para compreender tais normas.

\section{Conclusão}

O surdo é capaz de assumir responsabilidades e de adaptar-se às normas sociais. Mas, para isso precisa receber uma educação, doméstica e escolar, que o prepare para compreender tais normas, o contrário disso faz com que ele se torne uma pessoa incapaz de fato. Sendo assim, a incapacidade ou as muitas dificuldades que enfrentadas pelo surdo não se devem ao déficit auditivo, mas, de educação doméstica e escolar e a estrutura social inadequada para que ele tenha comportamentos dentro do padrão das normas sociais.

A partir desse ponto de vista muda-se o foco de discussão. Conforme já é encontrada em muitas publicações, deixa de ser a discussão deixa de ser sobre o déficit auditivo para ser a estrutura social e familiar em que o surdo é inserido. Se uma pessoa é exposta a uma educação que não o capacita a enfrentar as adversidades e a criar seu próprio espaço, ela dificiolmente conseguirá isso. Por outro lado, se essa pessoa ao lançar-se na sociedade em busca de seu espaço e encontra estruturas desfavoráveis diante de sua deficiência também não vai conseguir alcançar seu espaço. É importante perceber nessa discussão que a pessoa com deficiência precisa de diversos fatores para que atue na sociedade igualmente na sociedade como cidadão. A primeira estrutura que deve encontrar adaptada a sua especificidade é a família.

É preciso muito cuidado para que o surdo não seja superprotegido, porque esse tipo de proteção na verdade é uma forma de transformá-lo em uma pessoa dependente e, ainda pior, intransigente. Seu comportamento pode revelar que sua percepção do outro é de servidor, 
principalmente quando se trata de um ouvinte. As relações sociais acontecem pela interação com negociação e com delimitação de papéis e não por imposições.

Quando os papéis são distorcidos, as normas e as organizações dos grupos sociais perdem sua estrutura e isso prejudica o funcionamento e o crescimento de todo o grupo. $\mathrm{O}$ surdo para que seja e se sinta incluído na sociedade, precisa compreender os papéis que devem assumir nas diversas situações de interação.

O surdo ao não ser preparado para as interações sociais sentem muita dificuldade de pertencer a grupos e não se sente aceito. Esse sentimento de exclusão sempre traz muito sofrimento ao indivíduo, por isso, as narrativas de vida dos surdos são sempre acompanhadas de relatos de sofrimento e a figura do coitadinho é assumida por muitos surdos. Muitos deles se vêem uma pessoa impotente, quando na verdade a sua realidade pode ser diferente.

O surdo precisa é de oportunidade, que é gerada desde a sua preparação para enfrentar as adversidades da vida e não de pena. Esse sentimento de pena que faz com que as pessoas superprotejam as outras e a falta de tratamento adequado é que as tornam incapazes e não a deficiência auditiva.

\section{Referências}

AMARAL, L. A. Conhecendo a deficiência( em companhia de Hercules) São Paulo: Robel Editorial, 1995.

BRASIL. Lei Libras, 10.436 de 24 de abril de 2002. Dispõe sobre a Língua de Sinais

Brasileira -Libras. In: de: http://www.planalto.gov.br/ccivil_03/Leis/2002/L10436.htm. Acesso em 20 de abril de 2009. Acesso em 20 de abril de 2009.

BRASIL. Decreto $n^{0} 5.626$, de dezembro de 2005. Regulamenta a Lei ${ }^{0} 10.436$, de 24 de abril de 2002. Dispõe sobre a Língua Brasileira de Sinais - Libras, e o art. 18 da Lei $\mathrm{n}^{\mathrm{o}}$ 10.098, de 19 de dezembro de 2000. In:http://www.planalto.gov.br/ccivil_03/_ato20042006/2005/decreto/d5626.htm. Acesso em 20 de abril de 2009.

BRASIL. Lei da acessibilidade $\mathrm{n}^{\circ} 10.098$ de 19 de dezembro de 2000. Estabelece normas gerais e critérios básicos para a promoção da acessibilidade das pessoas portadoras de deficiência ou com mobilidade reduzida, e dá outras providências. In: http://www.planalto.gov.br/ccivil/LEIS/L10098.htm Acesso em 20 de abril de 2009.

BOWLBY, John. Apego e perda: apego: a natureza do vínculo. 3. ed. São Paulo: Martins Fontes, 2002. 
GLAT, Rosana; DUQUE, Maria Auxiliadora T. Convivendo com filhos especiais: o olhar paterno. Rio de Janeiro: 7Letras, 2003.

GOMES, Jerusa Vieira. “Socialização Primária: Tarefa Familiar?”. In: Cadernos de Pesquisa. São Paulo, n 91, nov. 1994, p. 54-61.

MIEIRO, Izabel Maria Carneiro. A influência materna na psicomotricidade e no desenvolvimento da linguagem do bebê. Universidade Candido Mendes [Monografia], Rio de Janeiro, 2003.

PERSKE, R. Thedignity of rissk. In:Wolfensberger,w (ed.): The Principle of Normalizationn in Human Services. Toronto: National Institute of Mental Retardation. 1972.

TANNURE, Cynthia C. Nascimento da criança deficiente: impactos sobre o psiquismo materno. Semana da Psicologia-Psicologia e saúde: práticas de desafios, 2007.

\section{Sobre as autoras:}

(1) Edneia de Oliveira Alves é Mestre em Psicologia Social pela Universidade Federal de Pernambuco e professora substituta do IFPB (Instituto Federal de Educação Ciência e Tecnologia da Paraíba). E-mail: edneia_o_alves@hotmail.com.

(2) Maysa Suelma Palmeira Leite Rocha é Acadêmica de Psicologia pela Faculdade Frassinetti do Recife. E-mail: Maysa.suelma@ig.com.br

\section{Como citar este artigo (Formato ISO):}

ALVES, Edneia O.; ROCHA, Maysa S.P.L. Quando o excesso de amor prejudica o desenvolvimento humano. Id on Line Revista de Psicologia - Edição Especial Educação e Saúde, set. 2009, vol.1, no.9, p.05-14. ISSN 1981-1189. 